ROLE MASTERY VOLUNTEER HRM

\title{
Volunteer Role Mastery and Commitment: Can HRM Make a Difference?
}

\begin{abstract}
Although the literature on human resource management (HRM) has provided compelling evidence that certain HRM practices can help employees attain the competence and confidence to carry out their role, less is known about the potential impact of HRM practices on volunteers in the context of non-profit organisations. This study addresses this gap by presenting a model that situates role mastery - operationalised as role clarity and self-efficacy - as its centrepiece. Our model suggests that role mastery leads to commitment to the volunteer organisation and that role mastery can be achieved through training and supportive relationships with paid staff. A dual-mediation analysis of survey data from a humanitarian non-profit organisation in the United Kingdom ( $n=647)$ supported our theoretical model. We contribute to volunteering theory and practice by identifying tools that non-profit organisations can employ to maximise the role mastery and commitment of volunteers.
\end{abstract}

Keywords: volunteering, training, supportive relationships with paid staff, role clarity, self-efficacy, organisational commitment 
ROLE MASTERY VOLUNTEER HRM

\section{Volunteer Role Mastery and Commitment: Can HRM Make a Difference?}

A wealth of research from the human resource management (HRM) scholarly community has shown that HRM practices have the capacity to create an environment in which employees not only understand their role, but also feel confident in their ability to carry it out (e.g., Bowen \& Ostroff, 2004; Kehoe \& Wright, 2013; Kinnie, Hutchinson, Purcell, Rayton, \& Swart, 2005). However, HRM research has mostly relied on samples of paid employees, leaving managers of volunteers to ponder whether HRM practices can likewise facilitate volunteers' role mastery and commitment to the non-profit organisation (e.g., Cuskelly, Taylor, Hoye, \& Darcy, 2006;

Nichols et al., 2005; Hager \& Brudney, 2004). The present study attempts to bridge this divide by presenting and testing a theoretical model that examines the extent to which the provision of training and a supportive work environment leads volunteers to experience role mastery, which, in turn, leads to higher levels of commitment.

At the heart of our theoretical model is role mastery (Feldman, 1981). Volunteers who master their role not only experience role clarity, in that they understand the tasks that are required to perform their role (Rizzo, House, \& Lirtzman, 1970), but they also experience high levels of self-efficacy, in that they are confident in their ability to carry out their assigned tasks successfully (Bandura, 1986).

A focus on role mastery is relevant in the context of volunteering for two reasons. First, a lack of role mastery is particularly salient in non-profit organisations, as research shows that volunteers often experience uncertainty with regard to their role and have low confidence because they feel unprepared for their volunteer activities (Haski-Leventhal \& Bargal, 2008; Kramer, 2011; Kramer, Meisenbach, \& Hansen, 2013). Second, research in the paid employment context shows that both role clarity (Mathieu \& Zajac, 1990; Newman \& Sheikh, 2012; Slattery, 
ROLE MASTERY VOLUNTEER HRM

Selvarajan, \& Anderson, 2008) and self-efficacy beliefs (e.g., Riggs \& Knight, 1994; Saks, 1995; van Vuuren, de Jong, \& Seydel, 2008) are positively related to organisational commitment. Finding ways to increase volunteer commitment is pressing, as in recent years, volunteering has become episodic, with individuals volunteering for shorter periods of time with numerous organisations (Snyder \& Omoto, 2008). Accordingly, we examine the extent to which role mastery ignites dedication in volunteers such that they express commitment toward the nonprofit organisation.

Our study also considers how HRM facilitates volunteers' role mastery via training and supportive work relationships with paid staff. We rely on the "ability-motivation-opportunity" (AMO) framework in HRM scholarship (e.g., Appelbaum, Bailey, Berg, \& Kallenberg, 2000; Delery \& Shaw, 2001; Lepak, Liao, Chung, \& Harden, 2006) to argue that training and supportive work relationships with paid staff help volunteers successfully fulfil their role by increasing their knowledge of the demands of the role and their confidence in their ability to perform it. In summary, this study presents a dual-mediation model that positions role mastery (operationalised as role clarity and self-efficacy) as the underlying mechanism in the relationship between training and paid staff support and organisational commitment.

In doing so, we make two contributions to the science and practice of volunteer management. First, we bring an HRM concept - role mastery - to the forefront of volunteering theory to show that it has important implications for the commitment of volunteers. Hence, we add to the growing body of literature showing that HRM is not only relevant to paid employees, but certain HRM practices can also be developed and implemented to shape the attitudes and behaviours of volunteers (e.g., Ferreira, Proenca, \& Proenca, 2012; Hidalgo \& Moreno, 2009; Newton, Becker, \& Bell, 2014). Moreover, we argue that role mastery mediates the relationship 
ROLE MASTERY VOLUNTEER HRM

between training and supportive relationships with paid staff and commitment, thereby

responding to Wilson's (2012) call to unearth the mechanism(s) that explain hypothesised relationships in the volunteering context.

Second, we leverage the AMO model to examine the extent to which training and paid staff support promote greater role mastery of volunteers. Although the volunteering literature is rich with information on how volunteers' subjective dispositions, such as personality traits, motives, and values, influence important outcomes (see Wilson, 2012), we know little about how HRM practices facilitate volunteers' beliefs that they are able and competent to perform their volunteer role. Doing so is especially relevant at a time when managers in non-profit organisations face increasing pressures for the greater professionalisation of their volunteer management practices (e.g., Ferreira et al., 2012; Hager \& Brudney, 2004; Kellock Hay, Beattie, Livingstone, \& Munro, 2001).

This paper is organised as follows. We first set up our argument for a positive relationship between role mastery and commitment to the volunteer organisation, and then turn to building hypotheses regarding the effects of training and supportive relationships with paid staff as antecedents of role mastery. These two lines of theory building culminate to produce mediation hypotheses. This is followed by an outline of the research methods and measures. After presenting the results, we discuss the findings and end with an acknowledgement of the study's limitations, together with a consideration of the consequences of the findings for theory and practice in the non-profit HRM context.

\section{Role Mastery and the Organisational Commitment of Volunteers}

Feldman (1981) defined role mastery as a combination of role clarity and self-efficacy beliefs. Role clarity is characterised by workers having an adequate amount of information 
ROLE MASTERY VOLUNTEER HRM

regarding what is required to perform their role (Rizzo et al., 1970), whereas self-efficacy is defined as the belief that one is capable of designing and carrying out specific tasks within a role (Bandura, 1986). We examine role mastery's relationship with affective organisational commitment, defined as an organisational member's “emotional attachment to, identification with, and involvement in the organisation" (Meyer \& Allen, 1991, p. 67). Although other forms of commitment are discussed in the literature, notably normative and continuance commitment, we focus on affective commitment because affective commitment is particularly important in the context of volunteerism (e.g., Boezeman \& Ellemers, 2008; Ohana, Meyer, \& Swatson, 2013).

There are at least two theoretical reasons that explain a positive relationship between role mastery and commitment. First, role mastery elicits commitment because volunteers' beliefs in their ability to complete tasks foster an attachment to the non-profit organisation's mission (Van Vuuren et al., 2008) and values (Doherty \& Hoye, 2011). In being competent and confident in their role, volunteers with high role mastery understand, contribute, and internalise the organisation's mission, thereby forming an attachment to the organisation.

Second, role mastery contributes to a person's positive self-regard. Volunteers who understand their role, and are confident in performing it, glean personal satisfaction and fulfilment from their role. This is because role mastery satiates their need for competence, which, according to self-determination theory, refers to people's innate need to successfully carry out challenging tasks and attain desired outcomes (Baard, Deci, \& Ryan, 2004). Conditions in the workplace that help satisfy this need have been shown to lead to employees' psychological adjustment and subsequent positive outcomes (e.g., Gagne \& Deci, 2005; Greguras \& Diefendorff, 2009). Because it is the organisation that provides volunteers with this platform to generate positive feelings and competency beliefs, volunteers reciprocate by forming an 
ROLE MASTERY VOLUNTEER HRM

emotional attachment to it. Hence, volunteers are committed because the organisation provides them with an opportunity to satiate their need for competence.

Although no research, to our knowledge, has simultaneously examined the impact of role clarity and self-efficacy on organisational commitment, research in both the paid employment (Mathieu \& Zajac, 1990; Newman \& Sheikh, 2012; Slattery et al., 2008) and volunteer contexts (Haski-Leventhal \& Cnaan, 2009; Nelson, Pratt, Carpenter, \& Walter, 1995; Sakires, Doherty, \& Misener, 2009) shows that role clarity is positively associated with organisational commitment. Research using samples of paid employees has found that self-efficacy is likewise positively associated with commitment (e.g., Riggs \& Knight, 1994; Saks, 1995; van Vuuren et al., 2008). Accordingly, we hypothesise:

Hypothesis 1. (a) Role clarity and (b) self-efficacy beliefs are positively related to volunteers' organisational commitment.

\section{The Effect of HRM Practices on Volunteer Role Mastery}

While most prior research on the impact of HRM practices on individual and organisational outcomes has focused on paid employees, a body of literature on the impact of HRM practices on volunteering is slowly emerging, showing that HRM practices have the capacity to influence volunteers' performance, well-being, and retention (see Studer \& von Schnurbein, 2013). Such findings are crucial to our understanding of how volunteers should be managed within non-profit organisations. Unlike paid employees, volunteers are typically not compensated monetarily for their work, so they are particularly receptive to organisational efforts that contribute to their personal development and adjustment to the environment (Ferreira et al., 2012). Therefore, HRM practices that make them feel appreciated, more comfortable in their role, or more closely connected to other members of the organisation should improve 
ROLE MASTERY VOLUNTEER HRM

volunteering outcomes. In the present study, we focus on the impact of volunteer training and supportive relationships with paid staff as HRM practices that have the potential to elicit these desired effects.

HRM scholars have long used the "ability-motivation-opportunity" (AMO) framework to explain the impact of HRM in the paid employment context. HRM practices that contribute to employees' ability to contribute to the organisation include recruitment, selection testing, and training that affect employees' type and level of knowledge and skills. HRM practices that motivate employees to higher levels of performance include individual and group incentives, along with merit-based pay, that stimulate discretionary effort and performance. Finally, HRM practices that provide employees with an opportunity to contribute to the organisation include information sharing and participation in decision making, factors that are developed through supportive social relationships with others (e.g., Appelbaum et al., 2000; Delery \& Shaw, 2001; Lepak et al., 2006).

An important question is whether the AMO model is helpful in understanding the impact of HRM in a volunteering context. Given that volunteers are not paid, motivation-enhancing practices that involve monetary remuneration do not seem to apply in this context. On the other hand, practices that promote volunteers' ability and opportunity to contribute to the volunteer organisation may be functional in increasing volunteers' role mastery, which, in turn, leads to other desirable outcomes, such as volunteers' commitment to their organisation. In the present study, we examine training (an ability-enhancing practice) and social support from paid staff (an opportunity-enhancing practice) as antecedents of role mastery.

The effect of training on volunteer role mastery. There is growing consensus in the literature that training contributes to positive individual and organisational outcomes in the 
ROLE MASTERY VOLUNTEER HRM

context of volunteering. For instance, a study conducted at four different non-profit organisations in the healthcare sector has shown that volunteers express appreciation for training opportunities provided to them by the organisation, which positively impacts their level of satisfaction (Ferreira et al., 2012). Moreover, at the organisational level, volunteer training can be crucial to the success of non-profit organisations, as the organisation's ability to fulfil its mission often hinges on the knowledge and skills of its volunteers (Akingbola, 2006; Kellock Hay et al., 2001). However, with many non-profit organisations experiencing a decline in their volunteer numbers, they often cannot be selective when recruiting volunteers (Taylor \& McGraw, 2006). As a result, new recruits may lack the skills needed to perform in their role and have low perceptions of role mastery due to a poor understanding of what the role entails and doubts about their ability to successfully perform it. This highlights the importance of volunteer training.

The purpose of training is to increase volunteers' abilities by fostering their learning. It is provided to organisational members to increase their knowledge of the organisation, their role, and how best to facilitate the organisation's goals. Moreover, training enables members to adjust to new ways of working. In this way, training satiates volunteers' need for competence by providing the needed clarity for organisational members to understand their role and contribute to the organisation (e.g., Ashforth, Sluss, \& Saks, 2007; Merrell, 2000; Wright \& Millesen, 2008). The argument that training provides role clarity is supported in the volunteering context by Wright and Millesen (2008). They found that the degree to which non-profit board volunteers understood their role was positively related to engagement with their role, and training was instrumental in increasing role clarity.

Moreover, training increases volunteers' confidence in their ability to perform their role (e.g., Newton et al., 2014). This is because training incorporates principles of social learning 
ROLE MASTERY VOLUNTEER HRM

theory, including the provision of time to practice newly-learned skills despite obstacles, an exemplar of how to perform the role well, and feedback on learning progress from trainers. Furthermore, training ignites positive feelings concerning the enactment of the activities that are required of volunteers (Bandura, 1986). This is consistent with research from the paid employment sector, which showed that training improves employees' self-efficacy beliefs (Gist \& Mitchell, 1992). Hence, training increases volunteers' ability, leading them to both understand their role and feel confident in their ability to carry out their volunteer work. Accordingly, we hypothesise:

Hypothesis 2. Training is positively associated with (a) role clarity and (b) self-efficacy beliefs.

The effect of supportive relationships on volunteer role mastery. Within the context of the AMO model, supportive relationships with paid staff provide volunteers with an opportunity to gain knowledge about their role, thereby achieving role mastery. Feeling supported by paid staff implies that volunteers are treated respectfully, can discuss their role with paid organisational members, ask questions if needed, share knowledge, and keep up-to-date on relevant initiatives or changes to their role or the organisation at large. Individuals typically perceive that role clarity is controllable by the organisation (Rhoades \& Eisenberger, 2002), so attempts by organisational staff to be supportive increase perceptions of role clarity. The notion that support from paid staff increases volunteers' role clarity perceptions is supported by a qualitative study of airport volunteers. The results showed that staff support from the volunteer organisation's paid staff led to increased task mastery among volunteers (McComb, 1995).

Supportive relationships with paid staff also increase self-efficacy beliefs, both through social persuasion and reduced anxiety over volunteers' role requirements (Bandura, 2012). 
ROLE MASTERY VOLUNTEER HRM

Specifically, support from the volunteer organisation's paid employees implies that they

encourage and persuade volunteers to believe in themselves and their abilities. Furthermore, the presence and help of paid staff reduces volunteers' anxiety about their ability to perform well in their role, which strengthens efficacy beliefs (Bandura, 2012). Therefore, as a result of the organisation's paid staff providing them with this support, volunteers feel better prepared and have greater confidence in their ability to successfully occupy their role. This argument is supported by findings from the paid employment context showing that organisational staff support boosts employees' self-efficacy perceptions (Tschannen-Moran \& Woolfolk Hoy, 2007). Therefore, we propose:

Hypothesis 3. Supportive relationships with paid staff are positively associated with (a) role clarity and (b) self-efficacy beliefs.

Our line of argumentation culminates in mediation hypotheses. Volunteers who perceive that they have adequate training and support from paid staff are more committed to the organisation because they understand their role requirements and feel confident in carrying out their role. These mediation hypotheses are consistent with social exchange theory (Blau, 1964), which posits that social support mechanisms are related to employee commitment because factors such as the provision of training and supportive work relationships signal to employees that they are valued members of the organisation. Providing volunteers with the needed role clarity and confidence to carry out their role signals to them that they are cared for, which is then reciprocated by volunteers in the form of commitment to the organisation. Hence, we hypothesise:

Hypothesis 4. Volunteers' perceptions of (a) role clarity and (b) self-efficacy mediate the link between training and volunteers' organisational commitment. 
ROLE MASTERY VOLUNTEER HRM

Hypothesis 5. Volunteers' perceptions of (a) role clarity and (b) self-efficacy mediate the link between supportive relationships with paid staff and volunteers' organisational commitment.

\section{Method}

\section{Sample and Procedure}

Data collection took place in a large religious non-profit organisation in the United Kingdom (UK) involved in international relief and development efforts. We invited 3,485 volunteers who were on the organisation's mailing list to participate in an electronic survey. A large number of these emails were undeliverable, bringing the number of potential respondents down to 2,500. A reminder email was sent three weeks after the initial correspondence. The survey remained open for seven weeks, during which time 647 questionnaires were returned to the research team, constituting a response rate of approximately 26 percent. Not all returned surveys were entirely complete, as the respondents were not compelled to answer all of the questions, given the voluntary nature of the survey. The final sample comprised 63.8 percent women; the average age was 56.15 years $(\mathrm{SD}=11.8)$ and participants had volunteered for the organisation for an average of 12.39 years $(\mathrm{SD}=9.83)$.

Although our response rate was in line with previous research using web-based surveys where participants are contacted via email alone (Kaplowitz, Hadlock, \& Levine, 2004), we employed two established methods for estimating nonresponse bias to assess the representativeness of the sample. First, we compared the sample to "known" population values on key demographic variables for volunteers in religious relief organisations in the UK (Armstrong \& Overton, 1977). Specifically, a comprehensive national survey of volunteering and charitable giving in the UK conducted by the Office of the Third Sector (2007) found that, 
ROLE MASTERY VOLUNTEER HRM

more than for any other type of non-profit organisation, the age distribution shifted to an older demographic when considering individuals volunteering for a religious organisation, which corresponds well to the age composition of our sample. Moreover, compared with men, women were more likely to volunteer for religious organisations (24 vs. 22 percent) and organisations engaged in international relief efforts (14 vs. 7 percent; Office of the Third Sector, 2007).

Second, we tested for any systematic differences between our respondents and those volunteers who decided not to complete our survey using an established procedure (Armstrong \& Overton, 1977). Specifically, we sorted our sample according to the date and time of the respondents' survey submission. The first 50 percent of the respondents were categorized as early respondents, while the other 50 percent were categorized as late respondents. We compared these two groups on the main study variables (i.e., training, paid staff support, role clarity, selfefficacy, organisational commitment) through a series of independent samples t-tests. We found that individuals who responded to our survey early did not differ significantly from late responders on any of the main study variables $(\mathrm{p}<.05)$. Based on the assumption that late respondents tend to be similar to nonrespondents (Armstrong \& Overton, 1977), we concluded that nonresponse bias did not unduly influence the representativeness of our sample.

\section{Measures}

Training. The measure for training was developed for this study based on previous work by Meyer and Smith (2000). The measure includes four items referring to satisfaction with training (e.g., "I am satisfied with the amount of training provided by [Organisation].") and the sufficiency of training received (e.g., "I need more training to carry out my volunteering activities," reverse-coded). The response scale ranged from 1 ("strongly disagree") to 7 (“strongly agree"). Cronbach’s Alpha was .70. 
ROLE MASTERY VOLUNTEER HRM

Supportive relationships with paid staff. We used three items from Eisenberger, Huntington, Hutchison, and Sowa (1986) and adapted them to reflect paid staff support efforts in the context of volunteering. A sample item was, "Paid staff at [Organisation] are supportive when I have a problem related to my volunteering." The response scale ranged from 1 ("strongly disagree") to 7 (“strongly agree"). Cronbach's Alpha was .88.

Role clarity. Role clarity was measured with four items based on a scale developed by Rizzo et al. (1970). The items were adapted to measure clarity of the volunteering role. A sample item was, "I know exactly what is expected of me as a volunteer." The response scale ranged from 1 ("strongly disagree”) to 7 (“strongly agree”). Cronbach’s Alpha was .90.

Self-efficacy. General self-efficacy was measured with the eight-item scale developed by Chen, Gully, and Eden (2001). A sample item was, "When facing difficult tasks, I am certain that I will accomplish them." The response scale ranged from 1 (“strongly disagree”) to 7 (“strongly agree"). Cronbach’s Alpha was .92.

Organisational commitment. Affective commitment to the organisation was measured with six items based on Meyer and Allen (1991). A sample item was, "[Organisation] has a great deal of personal meaning for me." The response scale ranged from 1 (“strongly disagree”) to 7 (“strongly agree"). Cronbach’s Alpha was .92.

Control variables. We entered gender $(1=$ female, $0=$ male $)$, age, and years volunteering for the organisation as controls in our analyses. We included these three variables because research has shown that gender (e.g., Matsuba, Hart, \& Atkins, 2007), age (e.g., Nelson et al., 1995), and tenure with an organisation (e.g., Boezeman \& Ellemers, 2007) can each impact volunteers' commitment to the organisation.

\section{Results}


ROLE MASTERY VOLUNTEER HRM

\section{Descriptive Statistics}

The means and standard deviations for each scale and inter-scale correlations for all study variables are presented in Table 1.

Insert Table 1 about here

\section{Preliminary Data Analysis}

As all the variables were collected from a single source, we carried out a series of confirmatory factor analyses (CFA) to assess the potential influence of common method variance and to establish discriminant validity of the scales (Podsakoff, MacKenzie, Lee, \& Podsakoff, 2003). We initially tested a full measurement model, in which all items loaded onto their respective factors. The five factors were allowed to correlate. Error terms were free to covary between one pair of training, self-efficacy, and organisational commitment items, respectively, to improve fit and help reduce bias in the estimated parameter values (Reddy, 1992). We used five fit indices to establish the goodness of fit of our model. For the $\chi^{2} / \mathrm{df}$, values of less than 2.5 indicate a good model fit and values around 5.0 an acceptable fit (Arbuckle, 2006). For the Tucker-Lewis coefficient (TLI) and the comparative fit index (CFI), values greater than 95 represent a good model fit and values greater than .90 an acceptable fit (Bentler, 1990). Finally, for the Root Mean Square Error of Approximation (RMSEA) and the Standardised Root Mean Square Residual (SRMR), values less than .08 indicate a good model fit (Browne \& Cudeck, 1993; Hu \& Bentler, 1998).

The five-factor model showed a good model fit $\left(\chi^{2}=1019 ; \mathrm{df}=262 ; \mathrm{TLI}=.92 ; \mathrm{CFI}=\right.$ $.93 ;$ RMSEA $=.068 ;$ SRMR $=.061)$. Next, sequential $\chi^{2}$ difference tests were carried out. Specifically, the full measurement model was compared to five alternative nested models, as shown in Table 2. Results comparing the measurement models reveal that the model fit of the 
ROLE MASTERY VOLUNTEER HRM

alternative models was significantly worse compared to the full measurement model (all at $\mathrm{p}<.001)$. Finally, we introduced an unmeasured latent methods factor to our original measurement model, allowing all items to load onto their theoretical constructs, as well as onto the latent methods factor. We assessed the change in CFI and RMSEA values between both models as an indicator of significance. The changes of CFI and RMSEA values, comparing both models, were 0.023 and 0.009 , which is below the suggested rule of thumb of 0.05 (Bagozzi \& $\mathrm{Yi}, 1990)$. These results indicate that the constructs in our study are distinct and that common method bias does not unduly influence the results.

Insert Table 2 about here

\section{Test of Hypotheses}

We employed latent variable structural equation modeling using AMOS 22.0 (Arbuckle, 2006) to test our theoretical model. We tested the model with and without the control variables (Becker, 2005). In the model with controls included, gender $(\beta=-.03)$ and age $(\beta=-.02)$ were not significantly related to organisational commitment, but the number of years volunteers had volunteered for the organisation was significantly related to commitment $(\beta=.16, p<.001)$. When it comes to the main study variables, there were minor differences in the obtained estimates between the models with and without controls, but this did not affect the conclusions that we draw from the results. In the present paper, we report the results for the model with the control variables included.

To examine whether role clarity and self-efficacy mediated the relationships between training and supportive relationships with paid staff and organisational commitment, we followed the steps outlined by Mathieu and Taylor (2006). The procedure compared three alternative models: saturated, direct effects, and indirect effects models. For the saturated model, 
ROLE MASTERY VOLUNTEER HRM

paths were estimated from each independent variable to role clarity, self-efficacy, and

organisational commitment, and direct paths from role clarity and self-efficacy to organisational

commitment. The saturated model provided an acceptable fit for the data $\left(\chi^{2}=1324 ; \mathrm{df}=338\right.$;

$\mathrm{TLI}=.90 ; \mathrm{CFI}=.91 ; \mathrm{RMSEA}=.07 ; \mathrm{SRMR}=.07)$.

For the direct effects model, direct paths were estimated from each independent variable

(i.e., training and supportive relationships with paid staff) to organisational commitment,

whereas no paths were leading to or stemming from the mediators (i.e., role clarity and self-

efficacy). The indirect effects model estimated direct paths from each independent variable to the

two mediator variables and direct paths from the mediator variables to the outcome variable (i.e., organisational commitment), with no direct effects between the independent variables and the outcome variable. Both the direct effects and the indirect effects models were nested within the saturated model, which enabled us to use chi-square difference tests to compare the statistical fit of the three models. Specifically, the difference in chi-square between the direct effects model and the saturated model, as well as between the indirect effects model and the saturated model, were tested for significance while accounting for the change in degrees of freedom between the models. The results are shown in Table 3.

Insert Table 3 about here

The direct effects model showed a relatively weak model fit $\left(\chi^{2}=1623 ; \mathrm{df}=344\right.$; TLI $=$ $.87 ; \mathrm{CFI}=.88 ; \mathrm{RMSEA}=.08 ; \mathrm{SRMR}=.15)$ and differed significantly from the saturated model $\left(\Delta \chi^{2}(6)=299, \mathrm{p}<.001\right)$. This indicates that at least one independent variable has a significant direct relationship with role clarity or self-efficacy, or that role clarity or self-efficacy are significantly related to organisational commitment, which lends further support to the importance of the mediator variables. The indirect effects model showed a better model fit $\left(\chi^{2}=1436\right.$; $\mathrm{df}=$ 
ROLE MASTERY VOLUNTEER HRM

$340 ; \mathrm{TLI}=.89 ; \mathrm{CFI}=.90 ; \mathrm{RMSEA}=.07 ; \mathrm{SRMR}=.08)$, but, again, differed significantly from the saturated model $\left(\Delta \chi^{2}(2)=112, \mathrm{p}<.001\right)$. This difference of fit indicates that one or both of the independent variables have a direct relationship with the outcome variable, pointing to a partially mediated model, rather than a fully mediated one.

In a next step, we used the indirect effects model as a base and subsequently added direct paths between the independent variables and the outcome variable. We kept paths in the model if they were significant and if adding them resulted in a significant improvement of the overall model fit. The fit statistics for the final model are presented in Table 3 . The standardised estimates of the final model are presented in Figure 1.

\section{Insert Figure 1 about here}

Parameter estimates in Figure 1 show that role clarity $(\beta=.14)$ and self-efficacy $(\beta=.08)$ were significantly related to organisational commitment, thereby supporting Hypotheses 1a and 1b. Training was significantly related to role clarity $(\beta=.44)$, lending support to Hypothesis 2 a, but not to self-efficacy, meaning that Hypothesis $2 \mathrm{~b}$ was not supported. Supportive relationships with paid staff were positively and significantly related to role clarity $(\beta=.28)$ and self-efficacy $(\beta=.16)$, supporting Hypotheses $3 \mathrm{a}$ and $3 \mathrm{~b}$, respectively. Because training $(\beta=.19)$ and supportive relationships with paid staff $(\beta=.37)$ were also both significantly related to organisational commitment, we only found support for a partially mediated, rather than a fully mediated model. Taken together, then, the final model indicated that the path between training and organisational commitment was partially mediated by role clarity, while the link between supportive relationships with paid staff and organisational commitment was partially mediated by role clarity and self-efficacy. Therefore, Hypotheses $4 \mathrm{a}, 5 \mathrm{a}$, and $5 \mathrm{~b}$ were partially supported. As the direct path from training to self-efficacy was not significant, we did not find support for 
ROLE MASTERY VOLUNTEER HRM

Hypothesis $4 \mathrm{~b}$, which predicted that self-efficacy would mediate the link between training and organisational commitment.

\section{Discussion}

Interest in the extent to which HRM has the capacity to bring about positive consequences in the context of volunteerism is mounting. The present study joins a small body of research that draws attention to ways in which HRM practices can assume a more strategic role in non-profit organisations and have a positive impact on volunteering outcomes (e.g., Cuskelly et al., 2006; Ferreira et al., 2012; Taylor \& McGraw, 2006). Our analyses showed that training and supportive relationships with paid staff played an important role in volunteers' successful fulfilment of their role. Specifically, our study showed that both practices facilitated volunteers' role mastery by increasing volunteers' knowledge of how their role should be carried out (i.e., role clarity) and their beliefs in their ability to successfully perform their role (i.e., self-efficacy). We further showed that role mastery, in turn, fostered volunteers' commitment to the organisation.

The present study contributes to the volunteering literature in at least three ways. First, we highlight the importance of role mastery to volunteering research. While role mastery has a long history in HRM research (Feldman, 1981), it has, to our knowledge, seldom been examined in the context of volunteering. This is surprising, given that the two dimensions of role mastery (i.e., role clarity and self-efficacy) arguably play a more salient role in volunteering than in paid employment due to the pervasiveness and persistence of role ambiguity and low confidence and efficacy beliefs among volunteers (Haski-Leventhal \& Bargal, 2008; Kramer, 2011; Kramer et al., 2013). In the present study, we show that role mastery promotes volunteers' commitment to the organisation. Future studies should build on our findings by exploring the utility of role 
ROLE MASTERY VOLUNTEER HRM

mastery as an explanatory variable in the relationship between HRM practices and outcomes in the context of volunteering.

Our focus on role mastery also highlights the importance of examining the nature and quality of volunteers' organisational experiences. Role mastery contributes to individuals' feelings of comfort and competence in an organisation, which are considered crucial to employees' adjustment and dedication to the organisation (Meyer \& Allen, 1991; Meyer, Irving, \& Allen, 1998). Future volunteering research should examine other factors that have been shown to contribute to individuals' feelings of comfort (e.g., organisational dependability, comfortable working conditions, freedom from conflict) and feelings of competence (e.g., autonomy, participation in decision making, job challenge) in the context of paid employment (Meyer \& Allen, 1991; Meyer et al., 1998). The field of volunteerism has typically been more concerned with why people volunteer in the first place, as opposed to experiences that keep individuals volunteering (Snyder \& Omoto, 2008). In light of the increasingly episodic nature of volunteering today, research that looks at factors that promote volunteers' role adjustment and, ultimately, their commitment, performance, and retention, is therefore particularly relevant and timely.

We further contribute to the literature by responding to a clarion call for research on the potential for HRM practices to make an impact on volunteer outcomes. Our contribution here is twofold. We first demonstrate that despite the significant differences between paid employees and volunteers (e.g., Brewster \& Lee, 2006; Cnaan \& Cascio, 1999; Pearce, 1993), certain HRM practices developed in the private sector are transferable to the third sector. By illustrating the utility of training and supportive relationships with paid staff in promoting role mastery and commitment in volunteers, we contribute to the emerging body of literature on the transferability 
ROLE MASTERY VOLUNTEER HRM

of knowledge from the private to the non-profit sector (e.g., Cuskelly et al., 2006; Nichols et al., 2005). We acknowledge, however, that different non-profit organisations will have different training needs and that volunteer attitudes toward organisational support efforts can vary, so a one-size-fits-all approach to supporting volunteers may not always be appropriate (Ferreira et al., 2012; Taylor \& McGraw, 2006).

We also respond to criticism that research in this area is seldom guided by theory (Wilson, 2012). Specifically, we leverage the AMO model to explain how training and supportive relationships with paid staff promote volunteers' role mastery by having a positive impact on their ability and providing them with opportunities to contribute to the organisation (Appelbaum et al., 2000; Delery \& Shaw, 2001; Lepak et al., 2006). We call on researchers to further explore the applicability of the AMO model to volunteerism by, for instance, investigating whether motivation-enhancing practices can also be effective in this context. We did not examine this dimension of the AMO framework in the present study because extrinsic motivators typically do not apply to volunteer work. However, future studies could explore whether other motivators, such as public praise and recognition, might have an effect on volunteering outcomes. Additionally, researchers could also examine how well the AMO model aligns with Clary et al.'s (1998) Volunteer Functions Inventory, which stipulates that individuals engage in volunteer activities in order to satisfy different motivations. Specifically, different ability-, motivation-, and opportunity-enhancing HRM practices may augment the degree to which the volunteer experience satisfies volunteers' motives and needs, particularly their need for understanding, meaningful relationships, and psychological growth, thereby contributing to the retention of volunteers (Clary \& Snyder, 1995; Clary et al., 1998). 
ROLE MASTERY VOLUNTEER HRM

The unexpected null finding for self-efficacy as the mediator between volunteer training and organisational commitment is worthy of comment. It is possible that our use of the general self-efficacy scale (Chen et al., 2001) may have accounted for this result. Training in the workplace is often specific to the tasks that employees perform in their role and has been shown to increase self-efficacy in employees by increasing their belief in their ability to perform specific tasks (Gist \& Mitchell, 1992). General self-efficacy, on the other hand, refers to individuals' beliefs in their ability to perform well across a variety of different situations (Chen et al., 2001; Judge, Erez, \& Bono, 1998). Thus, it is possible that volunteer training is related to task-specific self-efficacy. In addition, training in the context of volunteering tends to be short and fairly informal (Haski-Leventhal \& Bargal, 2008; Hidalgo \& Moreno, 2009), whereas paid staff support is generally ongoing. General self-efficacy can be resistant to temporary or ephemeral influences (Chen et al., 2001), which could explain why supportive relationships with paid staff increased volunteers' perceptions of self-efficacy, but training did not. Future studies should therefore look at task-specific self-efficacy as a potential mediator of the link between volunteer training and organisational commitment.

\section{Implications for Practice}

Our findings carry significant practical implications for non-profit organisations relying on volunteer labour. At a time when volunteer organisations are struggling to retain their volunteers and attract new members (Hidalgo \& Moreno, 2009; Taylor \& McGraw, 2006), our study highlights measures that managers in non-profit organisations can employ to ensure the ongoing commitment of their volunteers. For instance, volunteer organisations should invest in training by carrying out induction programs to facilitate volunteers' timely adjustment into their role. Training could include group meetings designed to introduce the organisation and its 
ROLE MASTERY VOLUNTEER HRM

mission to newcomers, meetings between new recruits and existing volunteers to discuss topics and experiences related to the beneficiaries of the organisation's services, and workshops to develop volunteers' general skills (e.g., communication, teamwork, etc.). Such an approach has been shown to be effective in promoting newcomers' successful adjustment into their role and maintaining a high level of service and professionalism among volunteers (Chen \& Wang, 2013).

In addition, training specific to the volunteer role should be conducted throughout a volunteer's tenure with the organisation. While non-profit organisations are typically underresourced and may thus focus more on short-term projects than on developing their human resources, such skills training is often instrumental in allowing organisations to provide their services (Akingbola, 2006; Kellock Hay et al., 2001). Moreover, due to the increasingly sporadic nature of volunteering and a decline in volunteer numbers, organisations often find themselves in a position where they are accepting volunteers who do not possess the skills necessary to perform a particular role (Taylor \& McGraw, 2006), which makes role-specific volunteer training all the more important. Training programs can include guidelines on how to successfully complete volunteer activities (e.g., campaigning), instructions on how to use certain tools (e.g., survey tools), or information about the context in which the organisation is operating (e.g., information about the political or economic situation in developing countries).

Managers can also facilitate regular interactions between paid staff and volunteers to ensure that volunteers feel supported by the organisation's paid staff. This can be accomplished by forming project teams that consist of volunteers and paid staff, organising gatherings where volunteers and paid staff can socialise, or assigning paid staff mentors to volunteers. These types of support efforts should contribute to volunteers feeling valued by the organisation and thereby foster their organisational commitment, as volunteers tend to appreciate feeling like they are part 
ROLE MASTERY VOLUNTEER HRM

of a team or having organisational staff show an interest in their personal development (Ferreira et al., 2012) and form a stronger attachment to the organisation in response (Blau, 1964).

Taken together, these measures call for human resource managers to assume an active role in the management of volunteers. This call is timely, as volunteer managers have been facing mounting pressures for greater adherence to managerialism, professionalism, and the related adoption of modern HRM practices (Cuskelly et al., 2006; Hager \& Brudney, 2004; Kellock Hay et al., 2001). Our findings show that non-profit organisations may benefit greatly from investing resources in organisational support efforts that extend beyond merely providing support to paid staff. To facilitate this change, non-profit organisations may wish to reconfigure or expand their HRM departments to include positions that are devoted entirely to supporting and managing the organisation's volunteer constituency. This is important because volunteers are typically not managed strategically within the HRM function; instead, their management is distributed across such functions as marketing, fundraising and campaigning, administration, and service delivery (Brewster \& Lee, 2006). HRM departments should thus assume a more central role in volunteer management, treating their volunteers as valuable and essential members (Chen \& Wang, 2013), while retaining the flexibility needed to accommodate the different expectations and commitment levels of volunteers.

Finally, due to the importance of role clarity in the successful management of volunteers (Merrell, 2000; Studer \& von Schnurbein, 2013), volunteer managers should also look at other strategies for reducing role ambiguity. For instance, one method that has been endorsed in the volunteering literature is the greater formalisation of roles through the use of job descriptions (Allen \& Mueller, 2013; Doherty \& Hoye, 2011; Merrell, 2000). Merrell (2000) suggested that non-profit organisations should formulate written guidelines that outline the role and scope of a 
ROLE MASTERY VOLUNTEER HRM

volunteer position, which lessens the potential for role ambiguity. However, volunteer managers should be careful not to narrow the scope of volunteer roles too much. Many volunteers value the opportunity to apply their individual talents and experiences; over-formalising roles could be counterproductive, making volunteer work more akin to employment than voluntary activity (Merrell, 2000). Organisations should therefore aim to develop written guidelines that clarify volunteers' responsibilities, but at the same time do not take away from the experience of volunteer work.

\section{Study Limitations}

Certain limitations should be considered when interpreting the results of our study. First, the cross-sectional design of the present study means that any causal inferences are tentative. Though our hypotheses were based on a sound theoretical foundation and we obtained evidence of concomitant variation by showing that our study variables covaried significantly and in the expected direction (Preacher \& Hayes, 2008), testing our predictions using a longitudinal design would provide more conclusive results.

Second, our response rate was relatively low (i.e., 26 percent) and our study sample consisted mostly of older, predominantly female volunteers from a religious non-profit organisation involved in international relief efforts, which may limit the generalisability of our findings. However, we did not find evidence of nonresponse bias and the gender and age profile of our sample was representative of the volunteer population in this particular domain. Nevertheless, future studies should look at other types of non-profit organisations and employ more demographically diverse samples to examine the phenomena under study here.

Third, we relied exclusively on self-report measures of the study variables. This raises the risk of common method variance (Podsakoff et al., 2003). However, following Conway and 
ROLE MASTERY VOLUNTEER HRM

Lance (2010) and Podsakoff et al. (2003), we took proactive design steps to minimise this concern by promoting participant anonymity and confidentiality of data and explaining study procedures clearly. In addition, we employed scales from the organisational behaviour literature with established construct validity. Finally, we used confirmatory factor analyses to provide evidence of discriminant validity (Conway \& Lance, 2010). Taken together, these steps enable us to assert with some degree of confidence that common method variance did not unduly influence our results.

\section{Conclusion}

Non-profit organisations often rely on volunteers to deliver their services, but are increasingly facing fierce competition for volunteer labour. A nascent body of volunteering research suggests that managers in non-profit organisations should adopt a more strategic approach to managing their volunteers in order to improve volunteering outcomes. This study makes an important contribution to this literature by showing that training and supportive relationships with paid staff promote role mastery through increased role clarity and self-efficacy perceptions among volunteers. This enables volunteers to successfully carry out their roles, which in turn fosters their commitment to the volunteer organisation. At a time when the demand for non-profit organisations' services is on the rise, but the funds needed to run these operations are increasingly subjected to budget cuts, we provide volunteer managers with HRM tools that they can use to manage their volunteers and thereby contribute to the smooth functioning of their organisations. 
ROLE MASTERY VOLUNTEER HRM

\section{References}

Akingbola, K. (2006). Strategy and HRM in non-profit organizations: Evidence from Canada. International Journal of Human Resource Management, 17(10), 1707-1725.

Allen, J. A., \& Mueller, S. L. (2013). The revolving door: A closer look at major factors in volunteers' intention to quit. Journal of Community Psychology, 41(2), 139-155.

Appelbaum, E., Bailey, T., Berg, P., \& Kalleberg, A. L. (2000). Manufacturing advantage: Why high-performance work systems pay off. Ithaca, NY: Cornell University Press.

Arbuckle, J. L. (2006). AMOS (Version 7.0) [computer software]. Chicago, IL: SPSS.

Armstrong, J. S., \& Overton, T. S. (1977). Estimating nonresponse bias in mail surveys. Journal of Marketing Research, 14, 396-402.

Ashforth, B. E., Sluss, D. M., \& Saks, A. M. (2007). Socialization tactics, proactive behaviour, and newcomer learning: Integrating socialization models. Journal of Vocational Behaviour, 70(3), 447-462.

Baard, P. P., Deci, E. L., \& Ryan, R. M. (2004). Intrinsic need satisfaction: A motivational basis of performance and well-being in two work settings. Journal of Applied Social Psychology, 34(10), 2045-2068.

Bagozzi, R. P., \& Yi, Y. (1990). Assessing method variance in multitrait-multimethod matrices: The case of self-reported affect and perceptions at work. Journal of Applied Psychology, 75(5), 547-560.

Bandura, A. (1986). Social foundations of thought and action: A social cognitive theory. Englewood Cliffs, NJ: Prentice-Hall.

Bandura, A. (2012). On the functional properties of perceived self-efficacy revisited. Journal of Management, 38(1), 9-44. 
ROLE MASTERY VOLUNTEER HRM

Becker, T. E. (2005). Potential problems in the statistical control of variables in organizational research: A qualitative analysis with recommendations. Organizational Research Methods, 8, 274-289.

Bentler, P. M. (1990). Comparative fit indexes in structural models. Psychological Bulletin, 107(2), 238-246.

Blau, P. M. (1964). Exchange and power in social life. New York, NY: John Wiley \& Sons, Inc.

Boezeman, E. J., \& Ellemers, N. (2007). Volunteering for charity: Pride, respect, and the commitment of volunteers. Journal of Applied Psychology, 92(3), 771-785.

Boezeman, E. J. \& Ellemers, N. (2008). Pride and respect in volunteers' organisational commitment. European Journal of Social Psychology, 38(1), 159-172.

Bowen, D. E., \& Ostroff, C. (2004). Understanding HRM-firm performance linkages: The role of the "strength" of the HRM system. Academy of Management Review, 29(2), 203-221.

Brewster, C., \& Lee, S. (2006). HRM in not-for-profit international organizations: Different, but also alike. In H. H. Larsen \& W. Mayrhofer (Eds.), Managing human resources in Europe (pp. 131-148). Retrieved from http://www.tandfebooks.com/action/showBook?doi=10.4324/9780203696736

Browne, M. W., \& Cudeck, R. (1993). Alternative ways of assessing model fit. In K. A. Bollen \& J. S. Long (Eds.), Testing structural equation models (pp. 136-162). Newbury Park, CA: Sage.

Chen, G., Gully, S. M., \& Eden, D. (2001). Validation of a new general self-efficacy scale. Organisational Research Methods, 4(1), 62-83. 
ROLE MASTERY VOLUNTEER HRM

Chen, W., \& Wang, Z. (2013). The discussion of the HRM practices and procedures in nonprofit organization: A case study of Sunshine Consulting Call Center. Canadian Social Science, 9(4), 28-33.

Clary, E. G., \& Snyder, M. (1995). Motivations for volunteering and giving: A functional approach. New Directions for Philanthropic Fundraising, 8, 111-123.

Clary, E. G., Snyder, M., Ridge, R. D., Copeland, J., Stukas, A. A., Haugen, J., \& Miene, P. (1998). Understanding and assessing motivations of volunteers: A functional approach. Journal of Personality and Social Psychology, 74(6), 1516-1530.

Cnaan, R. A., \& Cascio, T. A. (1999). Performance and commitment: Issues in management of volunteers in human service organisations. Journal of Social Service Research, 24, 1-37.

Conway, J. M., \& Lance, C. E. (2010). What reviewers should expect from authors regarding common method bias in organisational research. Journal of Business and Psychology, 25(3), 325-334.

Cuskelly, G., Taylor, T., Hoye, R., \& Darcy, S. (2006). Volunteer management practices and volunteer retention: A human resource management approach. Sport Management Review, 9(2), 141-163.

Delery, J. E., \& Shaw, J. D. (2001). The strategic management of people in work organizations: Review, synthesis and extension. Research in Personnel and Human Resource Management, 20, 165-197.

Doherty, A., \& Hoye, R. (2011). Role ambiguity and volunteer board member performance in non-profit sport organisations. Non-profit Management \& Leadership, 22(1), 107-128.

Eisenberger, R., Huntington, R., Hutchison, S., \& Sowa, D. (1986). Perceived organisational support. Journal of Applied Psychology, 71(3), 500-507. 
ROLE MASTERY VOLUNTEER HRM

Feldman, D. C. (1981). The multiple socialization of organization members. Academy of Management Review, 6(2), 309-318.

Ferreira, M. R., Proenca, T., \& Proenca, J. F. (2012). Organisational influence on volunteer satisfaction and attitudes towards HRM practices: The case of hospital volunteers. International Review on Public and Nonprofit Marketing, 9, 27-42.

Gagne, M., \& Deci, E. L. (2005). Self-determination theory and work motivation. Journal of Organizational Behavior, 26(4), 331-362.

Gist, M. E., \& Mitchell, T. R. (1992). Self-efficacy: A theoretical analysis of its determinants and malleability. Academy of Management Review, 17(2), 183-211.

Greguras, G. J., \& Diefendorff, J. M. (2009). Different fits satisfy different needs: Linking person-environment fit to employee commitment and performance using selfdetermination theory. Journal of Applied Psychology, 94(2), 465-477.

Hager, M. A., \& Brudney, J. L. (2004). Volunteer management practices and retention of volunteers. Washington, DC: The Urban Institute.

Haski-Leventhal, D., \& Bargal, D. (2008). The volunteer stages and transitions model: Organisational socialization of volunteers. Human Relations, 61(1), 67-102.

Haski-Leventhal, D., \& Cnaan, R. A. (2009). Group processes and volunteering: Using groups to enhance volunteerism. Administration in Social Work, 33(1), 61-80.

Hidalgo, M. C., \& Moreno, P. (2009). Organisational socialization of volunteers: The effect on their intention to remain. Journal of Community Psychology, 37(5), 594-601.

Hu, L., \& Bentler, P. M. (1998). Fit indices in covariance structure modelling: Sensitivity to underparameterized model misspecification. Psycgological Bulletin, 3(4), 424-453. 
ROLE MASTERY VOLUNTEER HRM

Judge, T. A., Erez, A., \& Bono, J. E. (1998). The power of being positive: The relation between positive self-concept and job performance. Human Performance, 11(2/3), 167-187.

Kaplowitz, M. D., Hadlock, T. D., \& Levine, R. (2004). A comparison of web and mail survey response rates. Public Opinion Quarterly, 68(1), 94-101.

Kehoe, R. R., \& Wright, P. M. (2013). The impact of high-performance human resource practices on employees' attitudes and behaviours. Journal of Management, 39, 366-391.

Kellock Hay, G., Beattie, R. S., Livingstone, R., \& Munro, P. (2001). Change, HRM and the voluntary sector. Employee Relations, 23(3), 240-255.

Kinnie, N., Hutchinson, S., Purcell, J., Rayton, B., \& Swart, J. (2005). Satisfaction with HR practices and commitment to the organisation: Why one size does not fit all. Human Resource Management Journal, 15(4), 9-29.

Kramer, M. W. (2011). A study of volunteer organisational membership: The assimilation process in a community choir. Western Journal of Communication, 75(1), 52-74.

Kramer, M. W., Meisenbach, R. J., \& Hansen, G. J. (2013). Communication, uncertainty, and volunteer membership. Journal of Applied Communication Research, 41(1), 18-39.

Lepak, D. P., Liao, H., Chung, Y., \& Harden, E. E. (2006). A conceptual review of human resource management systems in strategic human resource management research. Research in Personnel and Human Resources Management, 25, 217-271.

Mathieu, J. E., \& Taylor, S. R. (2006). Clarifying conditions and decision points for mediational type inferences in Organisational Behaviour. Journal of Organisational Behaviour, 27(8), 1031-1056. 
ROLE MASTERY VOLUNTEER HRM

Mathieu, J. E., \& Zajac, D. M. (1990). A review and meta-analysis of the antecedents, correlates, and consequences of organisational commitment. Psychological Bulletin, 108(2), 171194.

Matsuba, M. K., Hart, D., \& Atkins, R. (2007). Psychological and social-structural influences on commitment to volunteering. Journal of Research in Personality, 41, 889-907.

McComb, M. (1995). Becoming a travelers aid volunteer: Communication in socialization and training. Communication Studies, 46(3-4), 297-316.

Merrell, J. (2000). Ambiguity: Exploring the complexity of roles and boundaries when working with volunteers in well woman clinics. Social Science \& Medicine, 51(1), 93-102.

Meyer, J. P., \& Allen, N. J. (1991). A three-component conceptualization of organisational commitment. Human Resource Management Review, 1(1), 61-89.

Meyer, J. P., Irving, P. G., \& Allen, N. J. (1998). Examination of the combined effects of work values and early work experiences on organizational commitment. Journal of Organizational Behavior, 19(1), 29-52.

Meyer, J. P., \& Smith, C. A. (2000). HRM practices and organisational commitment: Test of a mediation model. Canadian Journal of Administrative Sciences/Revue Canadienne des Sciences de l'Administration, 17(4), 319-331.

Nelson, H. W., Pratt, C. C., Carpenter, C. E., \& Walter, K. L. (1995). Factors affecting volunteer long-term care ombudsman organisational commitment and burnout. Non-profit and Voluntary Sector Quarterly, 24(3), 213-233.

Newman, A., \& Sheikh, A. Z. (2012). Organisational commitment in Chinese small- and medium-sized enterprises: The role of extrinsic, intrinsic and social rewards. International Journal of Human Resource Management, 23(2), 349-367. 
ROLE MASTERY VOLUNTEER HRM

Newton, C., Becker, K., \& Bell, S. (2014). Learning and development opportunities as a tool for the retention of volunteers: A motivational perspective. Human Resource Management Journal, 24(4), 514-530.

Nichols, G., Taylor, P., James, M., Holmes, K., King, L., \& Garrett, R. (2005). Pressures on the UK volunteer sport sector. Voluntas: International Journal of Volunteer and Non-profit Organisations, 16(1), 33-50.

Office of the Third Sector (2007). Helping out: A national survey of volunteering and charitable giving. London, UK: Low, N., Butt, S., Ellis Paine, A., \& Davis Smith, J.

Ohana, M., Meyer, M., \& Swatson, S. (2013). Decision making in social enterprises: Exploring the link between employee participation and organisational commitment. Non-profit and Voluntary Sector Quarterly, 42(6), 1092-1110.

Pearce, J. L. (1993). Volunteers: The organizational behavior of unpaid workers. London, UK: Routledge.

Podsakoff, P. M., MacKenzie, S. B., Lee, J. Y., \& Podsakoff, N. P. (2003). Common method biases in behavioural research: A critical review of the literature and recommended remedies. Journal of Applied Psychology, 88(5), 879-903.

Preacher, K. J., \& Hayes, A. F. (2008). Contemporary approaches to assessing mediation in communication research. In A. F. Hayes, M. D. Slater, \& L. B. Snyder (Eds.), The Sage sourcebook of advanced data analysis methods for communication research (pp. 13-54). Thousand Oaks, CA: Sage Publications.

Reddy, S. K. (1992). Effects of ignoring correlated measurement error in structural equation models. Educational and Psychological Measurement, 52(3), 549-570. 
ROLE MASTERY VOLUNTEER HRM

Rhoades, L., \& Eisenberger, R. (2002). Perceived organisational support: A review of the literature. Journal of Applied Psychology, 87(4), 698-714.

Riggs, M. L., \& Knight, P. A. (1994). The impact of perceived group success-failure on motivational beliefs and attitudes: A causal model. Journal of Applied Psychology, 79(5), 755-766.

Rizzo, J. R., House, R. J., \& Lirtzman, S. I. (1970). Role conflict and ambiguity in complex organisations. Administrative Science Quarterly, 15(2), 150-163.

Sakires, J., Doherty, A., \& Misener, K. (2009). Role ambiguity in volunteer sport organisations. Journal of Sport Management, 23(5), 615-643.

Saks, A. M. (1995). Longitudinal field investigation of the moderating and mediating effects of self-efficacy on the relationship between training and newcomer adjustment. Journal of Applied Psychology, 80(2), 211-225.

Slattery, J. P., Selvarajan, T. T., \& Anderson, J. E. (2008). The influences of new employee development practices upon role stressors and work-related attitudes of temporary employees. International Journal of Human Resource Management, 19(12), 2268-2293.

Snyder, M., \& Omoto, A. M. (2008). Volunteerism: Social issues perspectives and social policy implications. Social Issues and Policy Review, 2(1), 1-36.

Studer, S., \& von Schnurbein, G. (2013). Organisational factors affecting volunteers: A literature review on volunteer coordination. Voluntas: International Journal of Volunteer and Nonprofit Organisations, 24(2), 403-440.

Taylor, T., \& McGraw, P. (2006). Exploring human resource management practices in nonprofit sport organisations. Sport Management Review, 9, 229-251. 
ROLE MASTERY VOLUNTEER HRM

Tschannen-Moran, M., \& Woolfolk Hoy, A. (2007). The differential antecedents of self-efficacy beliefs of novice and experienced teachers. Teaching and Teacher Education, 23(6), 944956.

Van Vuuren, M., de Jong, M. D. T., \& Seydel, E. R. (2008). Contributions of self and organisational efficacy expectations to commitment: A fourfold typology. Employee Relations, 30(2), 142-155.

Wilson, J. (2012). Volunteerism research: A review essay. Non-profit and Voluntary Sector Quarterly, 41(2), 176-212.

Wright, B. E., \& Millesen, J. L. (2008). Non-profit board role ambiguity: Investigating its prevalence, antecedents, and consequences. The American Review of Public Administration, 38(3), 322-338. 
ROLE MASTERY VOLUNTEER HRM

Table 1

Means, Standard Deviations, and Correlations for Scale Variables

\begin{tabular}{|c|c|c|c|c|c|c|c|c|c|}
\hline & Mean & s.d. & 1 & 2 & 3 & 4 & 5 & 6 & 7 \\
\hline 1. Gender & .64 & .48 & & & & & & & \\
\hline 2. Age & 56.15 & 11.80 & -.08 & & & & & & \\
\hline 3. Years Volunteering for Organisation & 12.39 & 9.83 & .04 & $.36^{* *}$ & & & & & \\
\hline 4. Training & 4.61 & 1.07 & $.12 * *$ & .04 & .07 & & & & \\
\hline 5. Supportive Relationships with Paid Staff & 5.82 & 1.04 & .05 & .01 & .02 & $.37 * *$ & & & \\
\hline 6. Role Clarity & 5.59 & 1.07 & $.13^{* *}$ & .01 & .05 & $.48^{* *}$ & $.49 * *$ & & \\
\hline 7. Self-Efficacy & 4.94 & .94 & .02 & $-.17 * *$ & -.05 & $.09 *$ & $.13^{* *}$ & $.14^{* *}$ & \\
\hline 8. Organisational Commitment & 5.49 & 1.11 & .03 & .00 & $.17 * *$ & $.28 * *$ & $.52 * *$ & $.44 * *$ & $.17 * *$ \\
\hline
\end{tabular}

Notes: $\mathrm{N}=647 ; * * \mathrm{p}<.01, * \mathrm{p}<.05$ 
ROLE MASTERY VOLUNTEER HRM

Table 2

Fit Statistics from Measurement Model Comparison

\begin{tabular}{|c|c|c|c|c|c|c|c|}
\hline Models & $\chi^{2}(d f)$ & $T L I$ & $C F I$ & $R M S E A$ & $S R M R$ & $\chi^{2}$ diff & $d f_{\text {diff }}$ \\
\hline Full measurement model & $1019(262)$ & .92 & .93 & .07 & .06 & & \\
\hline Model $\mathrm{A}^{\mathrm{a}}$ & $1348(266)$ & .88 & .90 & .08 & .07 & 329 & $4 * * *$ \\
\hline Model B ${ }^{b}$ & $2924(266)$ & .71 & .74 & .13 & .17 & 1905 & $4 * * *$ \\
\hline Model $\mathrm{C}^{\mathrm{c}}$ & $4397(271)$ & .56 & .60 & .16 & .17 & 3378 & $9 * * *$ \\
\hline Model $\mathrm{D}^{\mathrm{d}}$ & 4757 (269) & .52 & .57 & .16 & .18 & 3738 & $7 * * *$ \\
\hline $\begin{array}{l}\text { Model E }{ }^{\mathrm{e}} \\
\text { (Harman's single-factor test) }\end{array}$ & $5545(272)$ & .44 & .49 & .18 & .17 & 4526 & $10 * * *$ \\
\hline
\end{tabular}

Notes: $\mathrm{N}=647, * * * \mathrm{p}<.001 ; \chi^{2}=$ chi-square discrepancy; $\mathrm{df}=$ degrees of freedom; TLI=Tucker-Lewis coefficient; CFI=Comparative Fit Index; RMSEA=Root Mean

Square Error of Approximation; SRMR=Standardised Root Mean Square Residual; $\chi^{2}$ diff=difference in chi-square; $\mathrm{df}_{\text {diff }}=$ difference in degrees of freedom; in all measurement models, error terms were free to covary between one pair of training, self-efficacy, and organisational commitment items, respectively, to improve fit and help reduce bias in the estimated parameter values (Reddy, 1992). All models are compared to the full measurement model.

a $=$ Training and supportive relationships with paid staff combined into one factor

$\mathrm{b}=$ Role clarity and self-efficacy combined into one factor

$\mathrm{c}=$ Training, supportive relationships with paid staff, role clarity, and self-efficacy combined into one factor

$\mathrm{d}=$ Role clarity, self-efficacy, and organisational commitment combined into one factor

e=All constructs combined into one factor 
ROLE MASTERY VOLUNTEER HRM

Table 3

Structural Equation Model Comparison

\begin{tabular}{lccccc}
\hline \multicolumn{1}{c}{ Models } & $\chi^{2} / d f$ & TLI & CFI & RMSEA & SRMR \\
\hline Saturated model & $1324(338)$ & .90 & .91 & .07 & .07 \\
Direct effects model & $1623(344)$ & .87 & .88 & .08 & .15 \\
Indirect effects model & $1436(340)$ & .89 & .90 & .07 & .08 \\
Final model & $1325(339)$ & .90 & .91 & .07 & .07 \\
\hline Notes: N=647. Error terms were free to covary between one pair of training, self-efficacy, and organisational
\end{tabular}
commitment items, respectively, to improve fit and help reduce bias in the estimated parameter values (Reddy, 1992). 


\section{ROLE MASTERY VOLUNTEER HRM}

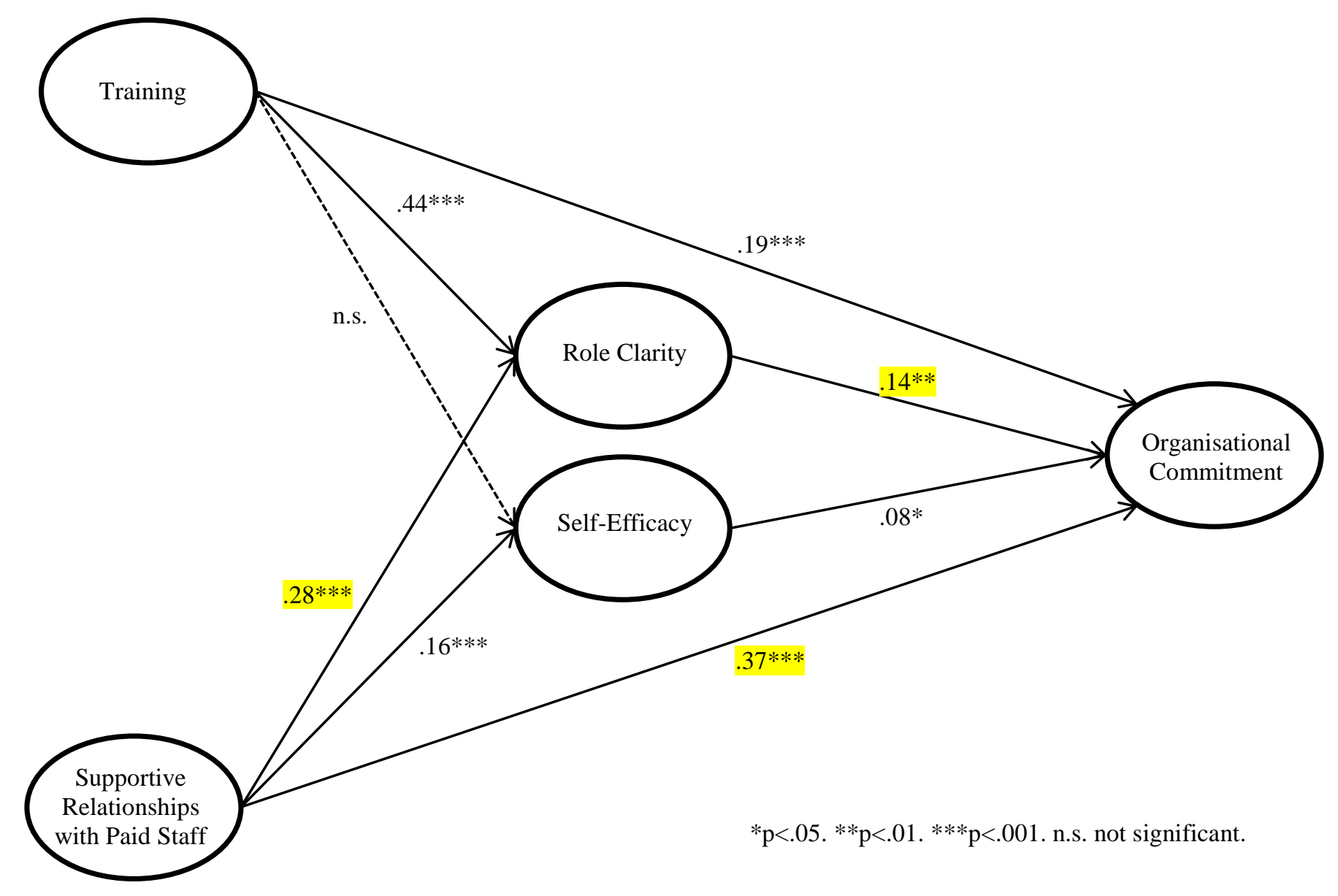

Figure 1. Standardised estimates of the final model. 